\title{
Distribution of dyslipidemia in Chinese early breast cancer patients at diagnosis and comparison of dyslipidemia incidence following different endocrine therapies: a population-based cohort study
}

\author{
Junren Wang \\ Sichuan University West China Hospital \\ Jin Yin \\ Sichuan University West China Hospital \\ Jiajun Qiu \\ Sichuan University West China Hospital \\ Jingwen Jiang \\ Sichuan University West China Hospital \\ Yao Hu \\ Sichuan University West China Hospital \\ Hong Zheng \\ Sichuan University West China Hospital \\ Ting Luo \\ Sichuan University West China Hospital \\ Xiaorong Zhong ( $\square$ zhongxiaorongzxr@163.com) \\ Sichuan University West China Hospital
}

Research article

Keywords: Breast cancer, Dyslipidemia, Endocrine therapy, Cohort study

Posted Date: March 13th, 2021

DOI: https://doi.org/10.21203/rs.3.rs-298866/v1

License: (c) (i) This work is licensed under a Creative Commons Attribution 4.0 International License. Read Full License 


\section{Abstract \\ Background}

Dyslipidemia increases the risk of cardiovascular disease death in breast cancer (BC). Based on the large West China Hospital (WCH) BC cohort, we aimed to clarify dyslipidemia prevalence at diagnosis and compare the risk of dyslipidemia induced by different endocrine and menopause status.

\section{Methods}

5917 EBC female patients recorded in WCH BC cohort, diagnosed between 2008.10 and 2017.04, were included for baseline analysis. 1883 patients receiving endocrine therapy (selective estrogen receptor modulator (SERM) or aromatase inhibitor (Al), with or without ovarian function suppression) with initial normal blood lipids were included for comparison study. Dyslipidemia was defined as abnormality of cholesterol/LDL/ $\mathrm{HDL}$ /triglyceride. Risk accumulation function was used to calculate the incidence of dyslipidemia to assess absolute risk, and the multivariate COX regression model was used to calculate the relative risk of dyslipidemia between groups.

\section{Results}

$16.5 \%$ of EBC patients had dyslipidemia at diagnosis. Among EBC patients receiving endocrine therapy, the accumulated incidence of dyslipidemia within 5 years in menopausal patients was higher than that in premenopausal patients (Adjusted HR [95\% Cl], 1.29 [1.04-1.59], 42.6 $\%$ vs $32.6 \%, P=0.0186)$. In premenopausal patients, the risk of abnormal TC in OFS + Al group was significantly higher than SERM group (adjusted HR, 3.50 [ 1.74-7.02], P<0.001, 5-year abnormal rate 22.0\% vs 3.5\%), and that of abnormal LDL-C was also increased(adjusted HR, 6.71 [ 3.16-14.26], $\mathrm{P}<0.001$, 5-year abnormal rate 12.2\% vs 1.4\%). In menopausal patients, the risk of abnormal TC or LDL-C showed the similar trend in Al group compared to SERM group.

\section{Conclusions}

Dyslipidemia is common concomitant disease in Chinese BC patients and needs to be closely monitored. Irrespective of menopause, Als treatment causes higher risk of TC/LDL-C dyslipidemia than SERM.

\section{Introduction}

Breast cancer is the most common malignant tumor in Chinese women ${ }^{1}$. Dyslipidemia, abnormal bone metabolism, mental anxiety and depression, as common concomitant diseases, are important contents of the full-course management of breast cancer ${ }^{2}$. Among them, dyslipidemia refers to the increase of serum cholesterol, TG or LDL-C, or the decrease of HDL-C ${ }^{3}$, while dyslipidemia is considered to be the main risk factor for ASCVD occurrence and development ${ }^{4,5}$. According to the epidemiological evidence in China, raised cholesterol is the most important and clear risk factor for ASCVD in China, while LDL-C rise is the third largest risk factor for cardiovascular disease death in China ${ }^{6}$. Cohort studies have found that cardiovascular death accounts for about $16.3 \%$ of the total deaths among breast cancer patients ${ }^{7}$. Compared with breast cancer patients without heart disease, breast cancer patients with heart disease have a $59 \%$ higher recurrence rate and a $60 \%$ higher mortality rate, and myocardial infarction can accelerate breast cancer progression and metastasis ${ }^{8}$. For breast cancer patients, it is very important to carry out blood lipid management in the early stage, in order to reduce the risk of heart disease.

Endocrine therapy is one of the standard treatments for estrogen receptor- positive breast cancer, which is mainly divided into selective estrogen receptor modulator (SERM) and aromatase inhibitor (Al) ${ }^{9}$. Different endocrine drugs may have different effects on blood lipid levels in patients with breast cancer. Previous clinical studies have shown that tamoxifen has good cardiovascular effects on postmenopausal breast cancer patients, including reducing total cholesterol and low-density lipoprotein cholesterol (LDL-C) levels, and increasing high-density lipoprotein cholesterol levels ${ }^{10,11}$. The ATAC trial compared the adverse reactions of anastrozole and tamoxifen in postmenopausal breast cancer patients, and the results of 100-month follow-up showed that the incidence of hypercholesterolemia in patients treated with anastrozole was significantly higher than that in patients treated with tamoxifen group ${ }^{12}$. Shien et.al found in a prospective clinical trial that TC and LDL-C levels at 12 and 24 months after toremifene treatment were higher than those in letrozole group ${ }^{13}$. A retrospective study found that in postmenopausal breast cancer patients, the abnormal level of triglyceride treated with letrozole for 24 months was higher than that of exemestane ${ }^{14}$

Therefore, the monitoring of dyslipidemia is very important. However, the proportion of dyslipidemia in Chinese breast cancer patients at initial diagnosis, the impact of different endocrine therapy on blood lipid in Chinese breast cancer patients, especially for premenopausal breast cancer patients, are still lack of large-scale real-world research evidence. Based on the large cohort of breast cancer in West China Hospital of Sichuan 
University, we analyzed the proportion and distribution of baseline dyslipidemia in early breast cancer patients, and compared the effects of different endocrine therapies such as SERM and AI on blood lipid levels in premenopausal and postmenopausal women respectively.

\section{Methods}

\subsection{West China Hospital Breast Cancer Cohort (WHC BC cohort)}

Patients pathologically diagnosed with breast cancer are prospectively registered in the Breast Cancer Information Management System (BCIMS) at West China Hospital, Sichuan University since 2008 15-17. Medical records, diagnostic pathology reports, treatments records are recorded by oncologists. All patients are followed by outpatient visit or telephone at 3 to 4-month intervals within 3 years after diagnosis, 6 -month intervals within 4-5 years, and then annually. The study was approved by the biomedical research ethics committee of West China Hospital (reference number: 20200427).

\subsection{Study Design}

Participants were breast cancer patients registered in BCIMS from October 6, 2008 to April 15, 2017. 1. EBC women data (See in Supplement Figure 1A) sets included:(1) Pathologically confirmed non-metastatic M0 female breast cancer patients;(2) At least one blood lipid test record within one month before diagnosis; Excluded: (1) No dyslipidemia diagnosis record at the time of diagnosis but taking hypolipidemic drugs;(2) Uncertain menstrual status. 2. EBC data sets with unchanging endocrine therapy (See in Supplement Figure 1B) included:(1) Pathologically confirmed non-metastatic M0 female breast cancer patients received standard endocrine therapy;(2) Blood lipid was detected within 3 months of endocrine therapy, and the level of blood lipid was normal; Excluded:(1) Dyslipidemia in the first 3 months of endocrine therapy; (2) Uncertain menstrual status.

\subsection{Definition of dyslipidemia}

The blood lipid test data were obtained through the LIS system of West China Hospital of Sichuan University. According to the "2016 Chinese guideline for the management of dyslipidemia in adults" ${ }^{3}, 1$. Any of the following conditions is defined as dyslipidemia, total cholesterol $\geq 6.2$ $\mathrm{mmol} / \mathrm{L}, \mathrm{LDL} \geq 4.1 \mathrm{mmol} / \mathrm{L}, \mathrm{HDL}<1.0 \mathrm{mmol} / \mathrm{L}$ or triglyceride $\geq 2.3 \mathrm{mmol} / \mathrm{L} ; 2$. ASCVD high-risk levels: LDL $\geq 4.9 \mathrm{mmol} / \mathrm{L}$ or total cholesterol $\geq 7.2$ $\mathrm{mmol} / \mathrm{L}$. In the EBC women dataset, if the level of any blood lipid index of a breast cancer patient at the time of diagnosis (including one month before diagnosis) reaches the abnormal standard of "2016 Chinese guideline for the management of dyslipidemia in adults", it is defined as an abnormality of this index and dyslipidemia. In the EBC women with endocrine therapy dataset, women with breast cancer who had normal blood lipid before endocrine therapy met the abnormal standard of "2016 Chinese guideline for the management of dyslipidemia in adults" during the 60 -month follow-up period, which was defined as abnormal of this index.

\subsection{Covariates}

Demographic characteristics (age, BMI) and clinical information (menstrual status, disease stage, ER, PR, HER2, endocrine therapy, etc.) were collected from WHC BC cohort. Past-history and history of taking lipid-lowering drugs were extracted from electronic medical records. SERM endocrine therapy includes tamoxifen (tamoxifen $\triangle \mathrm{TAM}$ ) and toremifene (Toremifene, TOR). Al includes anastrozole (Anastrozole $\ A N A)$, letrozole (Letrozole, LET) and exemestane (Exemestane, EXE). OFS (ovarian function suppression, OFS) includes goserelin drug castration or bilateral ovariectomy surgical castration. Past-history includes hypertension, diabetes and chronic kidney disease.

\subsection{Data Analysis}

Descriptive statistics were obtained for all study variables. Continuous variables are expressed as mean (SD) or median (interquartile range [IQR]) values. Categorical data are expressed as numbers (proportions). All categorical variables were compared for the study outcome by using the Fisher exact test or $\chi 2$ test, and continuous variables were compared using the t test or the Mann-Whitney U test, as appropriate. Multivariate logistic regression was used to find the independent risk factors for dyslipidemia at baseline.

A Cumulative Incidence analysis and a log-rank test were used to access the cumulative incidence rates of dyslipidemia which was used to assess the absolute risk of dyslipidemia during 60 months for patients with different endocrine therapy. Pairwise comparison between multiple groups was carried by log-rank test, which p-value was adjusted by Benjamini-Hochberg procedure. Multivariate Cox regression models, involving variables with a p-value less than 0.05 , were used to assess the relative risk for dyslipidemia among different group. We assessed the relative risk of dyslipidemia within 5 years among patients with different menopause status and endocrine therapy drugs. Data analysis and graph drawing are through $\mathrm{R}$ version 3.6.2. Statistical forms generated using Excel 2016 (Microsoft). For all the statistical analyses, $\mathrm{P}<0.05$ was considered significant.

\section{Results}




\subsection{Dyslipidemia in EBC dataset}

\subsubsection{Participants description}

A total of 5917 EBC patients were included in the EBC women data set. The median age was 47 years old [IQR, 42.00, 55.00], and the median BMI was 22.83 [20.83, 24.97]. The proportion of postmenopausal and non-menopausal female patients were $38.1 \%$ and $61.9 \%$ respectively. The baseline blood lipid levels were as follows: TC凶Median (IQR) , 4.66 [4.12, 5.29] mmol/L), TG凶Median (IQR), 1.10 [0.82, 1.54] mmol/L), HDL-C \Median (IQR), $1.56[1.32,1.84] \mathrm{mmol} / \mathrm{L})$, LDL-C Median (IQR), $2.59[2.16,3.10] \mathrm{mmol} / \mathrm{L})$.

\subsubsection{Prevalence of Dyslipidemia and Risk Factors}

At the initial diagnosis of EBC women data set, 978 cases (16.5\%) had dyslipidemia, and 75 / 978 cases (7.7\%) reached the high-risk blood lipid level of ASCVD. As shown in Table 2, the prevalence of dyslipidemia in the higher age group was higher than that in the lower age group ( $<<$ 0.001). The prevalence of dyslipidemia in each age group was 18-34 years old (6.4\%), 35-44 years old (9.7\%), 45-54 years old (16.7\%), 55-64 years old $(26.3 \%)$ and 65 years old $\varangle 28.7 \%$. The proportion of blood lipid reaching the high level of ASCVD was also statistically significant between age groups $(P=0.012)$. The proportion of dyslipidemia was also different between different BMI groups $(P<0.001)$, and the proportion of dyslipidemia in Obese group (22.9\%) or Overweight group (28.3\%) was higher than that in low BMI (8.3\%) or normal BMI group (12.9\%). The abnormal proportion of blood lipids in menopausal patients (25.7\%) was higher than that in non-menopausal patients (10.9\%), and there was a similar trend for blood lipids to reach the high-risk level of ASCVD (menopause (10.0\%) vs non-menopause $(4.2 \%), P=0.001)$. There was no significant difference in the prevalence of dyslipidemia among Subtypes, Stage and each hormone receptor group (ER, PR, Her2 and Ki67).

Age, BMI, menopause status, stage, ER, PR, HER2, Ki67 were included to construct binary multivariate logistic regression model. As shown in Figure 1, the risk of dyslipidemia was increased in both Overweight and Obese group compared with low BMI levels $₫$ Odds ratio [OR], Overweight: 2.69 [95\% Cl, 1.57-4.90], Obese: 2.27 [95\% Cl, 1.40-3.90]凶. Compared with the younger group (less than 35 years old), the risk of dyslipidemia was increased in the 55-64 and 65- age groups $₫$ Odds ratio [OR], 55-64: 1.86 [95\% Cl, 1.08-3.40] , 65-: 2.25 [95\% Cl, 1.14-3.90]凶. The prevalence of dyslipidemia in postmenopausal group was higher than that in non-menopausal group, and its prevalence of dyslipidemia increased $\mathbb{O} \mathrm{Odds}$ ratio [OR], 1.95 [95\% Cl, 1.51-2.50]凶.

\subsection{Dyslipidemia in EBC Endocrine Dataset}

\subsubsection{Dyslipidemia}

In this study, 1883 female patients with normal blood lipid before endocrine therapy were followed up for 60 months to monitor their blood lipid levels. Among them, there were 1258 non-menopausal cases, the median age was 43.00 years old [IQR, 39.00-47.00], the median BMI was 22.22 [IQR, 20.45-24.14], 298 cases had dyslipidemia within 60 months, and the median follow-up time was 24.40 months [IQR, 0.03, 60.00]. There were 625 postmenopausal patients, the median age was 57.00 years old [IQR, 52.00-62.00], the median BMI was 23.44 [IQR, 21.23-25.63], 207 patients had dyslipidemia within 60 months, and the median follow-up time was 20.06 months [IQR, 0.03, 60.00]. The incidence of dyslipidemia in one year in postmenopausal patients was significantly higher than that in non-menopausal patients $(25.2 \%[95 \% \mathrm{Cl}, 21.6 \%-28.7 \%]$ vs $16.8 \%$ [95\% $\mathrm{Cl}$, 14.6\%-18.9\%], $\mathrm{P}<0.001$; Supplement Table 1 and Supplement Figure 1). The 5-year risk of dyslipidemia in postmenopausal patients was also significantly higher than that in non-menopausal patients (Adjusted HR [95\%Cl], 1.29 [ $1.04-1.59$ ], P=0.0186; 42.6 \% vs 32.6\%, P<0.001; Supplement Table 1 and Supplement Figure 1).

\subsubsection{Abnormalities in Four Blood Lipid Indexes among Premenopause EBC}

We further analyzed the effect of specific endocrine therapy on the incidence of single index of dyslipidemia. The non-menopausal group received

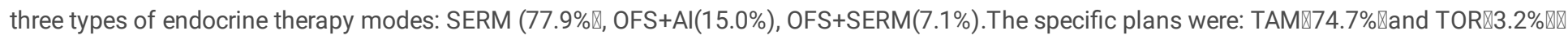

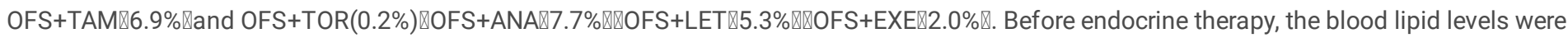

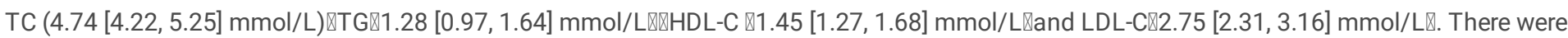
significant differences in the risk of TC and LDL-C abnormalities among the three groups $₫ T C$ : $P<0.001, L D L-C$ : $P<0.001 \otimes F i g u r e ~ 2 \Downarrow$. The results of

Pairwise log-rank test showed that compared with SERM group, the 1-year abnormal incidence of TC and LDL-C in OFS + AI Group was significantly higher囚TC: OFS+AI vs SERM, 22\% vs 3.5\%, P<0.001; LDL-C: OFS+AI vs SERM, $12.2 \%$ vs $1.4 \%, P<0.001$; Supplement Table 2 and Supplement Table 4邓;the 5-year abnormal incidence of TC and LDL-C in OFS + AI Group was also significantly higher囚TC: OFS+AI vs SERM, 22.0\% vs 3.5\%, P<0.001; LDL-C: OFS+AI vs SERM, $12.2 \%$ vs $1.4 \%, P<0.001$; Supplement Table 2 and Supplement Table $4 \rrbracket$. In the subgroup analysis of specific drugs, we found that compared with TAM group, the 5-year incidence of TC and LDL-C in OFS+ANA or OFS+LET was significantly increased, and the difference between OFS + ANA and OFS + LET was not significant $₫$ Supplement Table 2 and Supplement Table 6冈. In order to determine the relative risk of different treatment modes or drugs in the occurrence of TC abnormality and LDL-C abnormality, we constructed a multivariate COX regression model, the factors with significant single factor COX regression $\mathrm{P}$ value between the corresponding groups were included for correction, and it was found that the OFS + Al group had a higher risk of LDL-C abnormality than the SERM group (Adjusted HR [95\% Cl], 6.71 [ 3.16 - 14.26], p<0.001囚and a higher risk of TC abnormality (Adjusted HR [95\%Cl], 3.50 [ 1.74 - 7.02], p<0.001】. Compared with TAM, 
OFS + ANA or OFS + LET had higher probability of LDL-C abnormal risk冈OFS+ANA vs TAM: Adjusted HR [95\%Cl], 10.86 [ 4.59 - 25.71], p<0.001; OFS+LET vs TAM: Adjusted HR [95\%Cl], 3.66 [ 1.01 - 13.30], $p=0.049 \llbracket a n d$ TC abnormal risk 0 OFS+ANA vs TAM: Adjusted HR [95\%Cl], 4.05 [ 1.72 9.55], $p=0.001$; OFS+LET vs TAM: Adjusted HR [95\% Cl], 4.66 [ 2.02 - 10.72], p<0.001囚, and the others are shown in Table 3. However, there was no statistical difference in TG and HDL-C between different endocrine therapy groups in premenopausal patients $₫$ Supplement Figure 2 $₫$.

\subsubsection{Abnormalities in Four Blood Lipid Indexes among Menopause EBC}

For the menopausal group, SERM (26.2\%) and AI (73.8\%) were used as endocrine therapy, the specific therapeutic drugs were: TAM $₫ 25.1 \% \bigotimes$ and

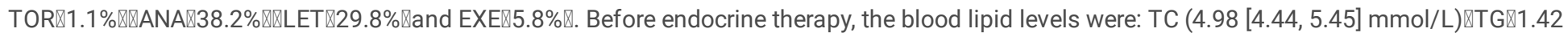

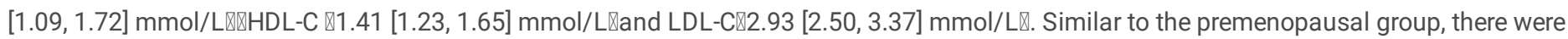
significant differences in the risk of abnormal TC and LDL-C between SERM therapy and Al therapy $\varangle$ TC: $P<0.001, L D L-C$ : $P=0.002 \otimes F i g u r e ~ 3 \varangle$. The incidence of 1-year abnormal TC in Al group was higher than that in SERM group $₫$ AI vs SERM, 13.9\% vs 4.5\%, P=0.002; Supplement Table 3 and

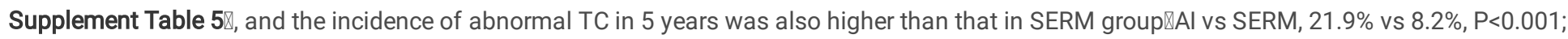
Supplement Table 3 and Supplement Table 5囚. Compared with SERM group, the 1-year incidence of abnormal LDL-C in Al group did not increase

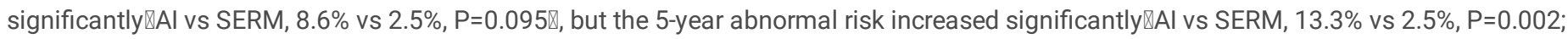

Supplement Table 3 and Supplement Table 5 $₫$. Similarly, in the subgroup analysis of specific drugs, we found the same trend as premenopausal : the incidence of abnormal TC and LDL-C in 1 year and 5 years of OFS + ANA or OFS + LET was significantly higher than that in TAM group, and the difference between OFS + ANA and OFS + LET was not significant $₫$ Supplement Table 3 and Supplement Table 7 . Multivariate COX regression

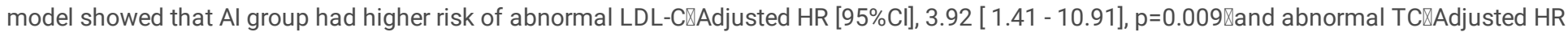

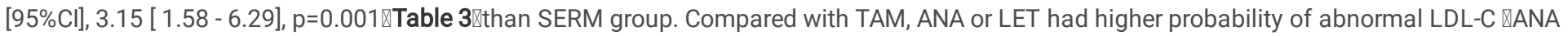
vs TAM: Adjusted HR [95\%Cl], 6.17 [ 1.87 - 20.37], p=0.003; LET vs TAM: Adjusted HR [95\%Cl], 5.00 [ 1.46 - 17.07], p=0.010冈and TC abnormal $\llbracket A N A$ vs TAM: Adjusted HR [95\%Cl], 4.07 [ 1.92 - 8.62], p<0.001; LET vs TAM: Adjusted HR [95\%Cl], 2.77 [ 1.25 - 6.10], p=0.012区. There was no statistical difference in TG and HDL-C between different endocrine therapy groups in postmenopausal patients $\triangle$ Supplement Figure 3区.

\section{Discussion}

This study is currently the largest single-center breast cancer blood lipid cohort study in China. This study found that $16.6 \%$ of patients with early breast cancer had dyslipidemia at the time of first diagnosis, and older age, high BMI levels and menopause were all independent risk factors for dyslipidemia. In EBC patients receiving endocrine therapy, the risk of dyslipidemia in menopausal patients was still higher than that of nonmenopausal patients. For the premenopausal group, the risk of abnormal TC and LDL-C in 1 year or 5 years in OFS + Al Group was significantly higher than that in SERM group. For postmenopausal patients, the 1-year or 5-year risk of abnormal TC in Al group was significantly higher than that in SERM group, and the 5-year risk of abnormal LDL-C in Al group was significantly higher than that in SERM group.

The baseline blood lipid characteristics of patients with EBC are different in China and abroad. Bahl et al. examined blood lipids in 535 breast cancer patients in Canada. The results showed: TC(mean [SD], 5.0 [1.0] mmol/L),TG(mean [SD], 1.3 [0.7] mmol/L) $\mathrm{mHDL}-\mathrm{C}(\mathrm{mean}$ [SD], 1.4 [0.4] $\mathrm{mmol} / \mathrm{L})\left[\mathrm{LDL}-\mathrm{C}(\right.$ mean $[S D], 2.9[0.9] \mathrm{mmol} / \mathrm{L}){ }^{18} \square \mathrm{A}$ prospective cohort study in Norway reported that the blood lipid levels of breast cancer patients at first diagnosis were: TC(mean [SD], 5.82 [1.3] mmol/L) $1 \mathrm{TG}\left(\right.$ mean [SD], 1.2 [0.8] mmol/L) and HDL-C(mean [SD], 1.8 [0.4] mmol/L) ${ }^{19}$. A study of 1054 newly diagnosed breast cancer patients in Chongqing, China showed that TC, mean [SD], 4.5 [0.9] mmol/L; TG, mean [SD], 1.3 [1.0] mmol/L; HDL-C, mean [SD], 1.4 [0.4] mmol/L; LDL-C, mean [SD], 2.8 [0.8] mmol/L) ${ }^{20}$. The baseline blood lipid levels of newly diagnosed early breast cancer patients in our study were similar to those in Chongqing, but better than those reported in Canada and Norway. Several studies have shown that compared with western countries, Chinese breast cancer patients are younger at initial diagnosis, with an average age of $45-55^{21}$ and a lower BMI

22 , which leads to a lower baseline blood lipid level in Chinese breast cancer patients than those in western countries.

At present, there is little evidence about the risk factors of dyslipidemia in breast cancer patients. Li et al. conducted a sample survey of 5375 people in Chongqing, China, and found that high BMI and high age were independent risk factors for female dyslipidemia ${ }^{23}$. Several epidemiological studies showed that the level of dyslipidemia in postmenopausal women was significantly higher than that in premenopausal women ${ }^{24}$. This study confirmed that high age, high BMI level and menopause are independent risk factors for dyslipidemia in women with early breast cancer, which is consistent with the above research results. Therefore, whether premenopausal or postmenopausal, physicians should pay attention to their dyslipidemia, especially for people undergoing endocrine therapy after menopause, which will help to monitor the occurrence of cardiovascular events.

In China, the full-course management of breast cancer and its associated diseases is receiving more and more attention ${ }^{2}$. However, the occurrence time and incidence of dyslipidemia in hormone positive EBC patients, especially in premenopausal patients after receiving different endocrine therapy are still not clear. This study found that after endocrine therapy, the incidence of dyslipidemia in 5 years of menopausal patients is higher than that of non-menopausal patients, just like the incidence of dyslipidemia in 1 year, with the incidence of $42.6 \%$ and $32.6 \%$ in menopausal and non-menopausal patients respectively. The risk of abnormal TC and LDL-C in premenopausal breast cancer patients in one or five years showed a trend: OFS + AI Group was significantly higher than SERM group, OFS + LET or OFS + ANA group was significantly higher than TAM group. While

Page 5/15 
for postmenopausal EBC women, the risk of abnormal TC and LDL-C was also higher in Al group than that in SERM group, which was consistent with the clinical reports of early hormonal receptor- positive BC in endocrine therapy ${ }^{13,25-27}$. This suggests that more than one third of premenopausal and postmenopausal women with breast cancer may have dyslipidemia after long-term endocrine therapy, and SERM is more likely to cause the changes of TC and LDL-C than Al, which are the two important risk factors of cardiovascular disease.

This study has some limitations. The research object of this study comes from the single-center cohort of West China Hospital of Sichuan University in Western China, which does not represent the total population of China. This study focused on the incidence of dyslipidemia, and did not further explore the incidence of ASCVD and cardiovascular disease.

\section{Conclusion}

This study is based on the analysis of a large-sample breast cancer cohort in China, and found that $16.6 \%$ of early breast cancer patients in China had dyslipidemia at the time of diagnosis. Older age, high BMI and menopause were risk factors for dyslipidemia. Among the hormone receptorpositive EBCs with normal blood lipids, dyslipidemia occurred in about 1 / 3 of the patients within 5 years after receiving endocrine therapy, and the dyslipidemia rate of menopausal patients was higher than that of non-menopausal patients in the first year. The incidence of TC and LDL-C abnormalities after Al treatment was higher than that in SERM group in menopausal and non-menopausal patients. This suggests that dyslipidemia is one of the most common concomitant diseases of breast cancer. When physicians make endocrine decisions, they need to consider that $\mathrm{Al}$ is more likely to cause abnormal TC and LDL-C than SERM, and these two indicators are risk factors of cardiovascular disease. For patients who have received endocrine therapy, whether premenopausal or postmenopausal, dyslipidemia is very common and must be closely detected. This study provides important clinical data for the full-course management strategy of breast cancer hyperlipidemia.

\section{Declarations}

\section{Ethics approval and consent to participate:}

The study was conducted in accordance with the principles of the Declaration of Helsinki. This study was also approved by the biomedical research ethics committee of West China Hospital (reference number: 20200427).

\section{Consent for publication}

Not applicable

\section{Availability of data and materials}

The data are available for all study authors. The datasets used and analysed during the current study are available from the corresponding author on reasonable request.

\section{Competing interests}

We declare no competing interests.

Funding This work was supported by the National Key Development Plan for Precision Medicine Research (grant number 2017YFC0910004), and the 135 projects for disciplines of excellence, West China Hospital, Sichuan University (grant number: ZYGD18012).

\section{Author Contributions}

XZ and TL were responsible for the study's concept and design. JW, JY, JQ, JJ, and YH were responsible for data and project management. JW, JY, $\mathrm{JQ}$, and JJ performed the data cleaning and analysis. JW, XZ, and TL interpreted the data. JW, JY, JQ, JJ, YH, HZ, TL, and XZ drafted and revised the manuscript. All the authors approved the final manuscript as submitted and agree to be accountable for all aspects of the work.

\section{Acknowledgment}

Not applicable

\section{References}

1 Chen, W. et al. Cancer statistics in China, 2015. CA Cancer J. Clin.66, 115-132 (2016).

2 Ma, F., Xu, B. \& Shao, Z. Comprehensive management guideline for breast cancer follow-up and concomitant diseases. Zhonghua Zhong liu za zhi [Chinese Journal of Oncology]41, 29-41 (2019). 
3 Zhu, J. \& GR, Z. S. Guidelines for prevention and treatment of dyslipidemia in Chinese adults (revised 2016). Chinese Circulation Journa/31, 937953 (2016).

4 Jacobson, T. A. et al. National lipid association recommendations for patient-centered management of dyslipidemia: part 1-full report. J. Clin. Lipidol.9, 129-169 (2015).

5 Tabas, I., Williams, K. J. \& Borén, J. Subendothelial lipoprotein retention as the initiating process in atherosclerosis: update and therapeutic implications. Circulation116, 1832-1844 (2007).

6 Hu, S. Report on Cardiovascular Health and Diseases in China 2019: an Updated Summary. Chinese Circulation Journa/35 (2019).

7 Abdel-Qadir, H. et al. A population-based study of cardiovascular mortality following early-stage breast cancer. JAMA cardiology2, 88-93 (2017).

8 Koelwyn, G. J. et al. Myocardial infarction accelerates breast cancer via innate immune reprogramming. Nat. Med.26, 1452-1458 (2020).

9 Lumachi, F. et al. Endocrine therapy of breast cancer. Curr. Med. Chem.18, 513-522 (2011).

10 Bruning, P. et al. Tamoxifen, serum lipoproteins and cardiovascular risk. British journal of cancer58, 497-499 (1988).

11 Grainger, D. J. \& Schofield, P. M. Tamoxifen for the prevention of myocardial infarction in humans: preclinical and early clinical evidence. Circulation112, 3018-3024 (2005).

12 Arimidex, T. Comprehensive side-effect profile of anastrozole and tamoxifen as adjuvant treatment for early-stage breast cancer: long-term safety analysis of the ATAC trial. The lancet oncology7, 633-643 (2006).

13 Shien, T. et al. Serum lipid and bone metabolism effects of Toremifene vs. Letrozole as adjuvant therapy for postmenopausal early breast cancer patients: results of a multicenter open randomized study. Cancer Chemother. Pharmacol.81, 269-275 (2018).

14 Tian, W., Wu, M. \& Deng, Y. Comparison of Changes in the Lipid Profiles of Eastern Chinese Postmenopausal Women With Early-Stage Breast Cancer Treated With Different Aromatase Inhibitors: A Retrospective Study. \#N/A7, 837-843 (2018).

15 Liu, P. et al. Optimizing Survival Analysis of XGBoost for Ties to Predict Disease Progression of Breast Cancer. IEEE Transactions on Biomedical Engineering (2020).

16 Zhong, X. et al. Multidimensional Machine Learning Personalized Prognostic Model in an Early Invasive Breast Cancer Population-Based Cohort in China: Algorithm Validation Study. JMIR medical informatics8, e19069 (2020).

17 Luo, C. et al. Nomogram predicting locoregional recurrence to assist decision-making of postmastectomy radiation therapy in patients with T12 N1 breast cancer. International Journal of Radiation Oncology* Biology* Physics103, 905-912 (2019).

18 Bahl, M. et al. Serum lipids and outcome of early-stage breast cancer: results of a prospective cohort study. Breast Cancer Res. Treat.94, 135144 (2005).

19 Lofterød, T. et al. Impact of pre-diagnostic triglycerides and HDL-cholesterol on breast cancer recurrence and survival by breast cancer subtypes. BMC cancer18, 654 (2018).

$20 \mathrm{Li}, \mathrm{X}$. et al. Status of lipid and lipoprotein in female breast cancer patients at initial diagnosis and during chemotherapy. Lipids Health Dis.17, 91 (2018).

21 Fan, L. et al. Breast cancer in China. The lancet oncology15, e279-e289 (2014).

$22 \mathrm{Hao}$, Y. et al. Long-term excess body fat in adulthood and the risk of pre-and postmenopausal breast cancer in Chinese women. Breast Cancer Res. Treat. (2020).

23 Qi, L. et al. Prevalence and risk factors associated with dyslipidemia in Chongqing, China. International journal of environmental research and public health12, 13455-13465 (2015).

24 Phan, B. A. P. \& Toth, P. P. Dyslipidemia in women: etiology and management. International journal of women's health6, 185 (2014).

25 Yamamoto, Y. \& Iwase, H. J. I. j. o. c. o. Safety profiles of aromatase inhibitors and selective estrogen-receptor modulators in the treatment of early breast cancer. 13, 384-394 (2008). 
26 Lewis, S. J. A. h. j. Do endocrine treatments for breast cancer have a negative impact on lipid profiles and cardiovascular risk in postmenopausal women? 153, 182-188 (2007).

27 Connor, C. \& Attai, D. J. A. o. s. o. Adjuvant endocrine therapy for the surgeon: options, side effects, and their management. 20, 3188-3193 (2013).

\section{Tables}




\begin{tabular}{|c|c|c|}
\hline & Group & Value \\
\hline Age, median (IQR) & & $47.00[42.00,55.00]$ \\
\hline Mean (SD) & & $48.43(10.04)$ \\
\hline Sex & Female & $5917(100.0 \%)$ \\
\hline BMI, median (IQR) & & $22.83[20.83,24.97]$ \\
\hline Mean (SD) & & $23.08(3.10)$ \\
\hline \multirow[t]{2}{*}{ Menopause status, No (\%) } & Yes & $2253(38.1 \%)$ \\
\hline & No & 3664 (61.9) \\
\hline \multirow[t]{5}{*}{ Stage, No (\%) } & 0 & $223(3.8 \%)$ \\
\hline & प & $1334(22.5 \%)$ \\
\hline & 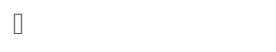 & $2766(46.7 \%)$ \\
\hline & प & $1294(21.9 \%)$ \\
\hline & Unknown & $300(5.1 \%)$ \\
\hline \multirow[t]{6}{*}{ pT status, No (\%) } & 0 & $245(4.1 \%)$ \\
\hline & 1 & $2062(34.8 \%)$ \\
\hline & 2 & $2843(48.0 \%)$ \\
\hline & 3 & $229(3.9 \%)$ \\
\hline & 4 & $247(4.2 \%)$ \\
\hline & Unknown & $291(4.9 \%)$ \\
\hline \multirow[t]{5}{*}{ pN status, No (\%) } & 0 & $3094(52.3 \%)$ \\
\hline & 1 & $1681(28.4 \%)$ \\
\hline & 2 & $619(10.5 \%)$ \\
\hline & 3 & $497(8.4 \%)$ \\
\hline & Unknown & $26(0.4 \%)$ \\
\hline \multirow[t]{6}{*}{ Molecular Subtype, No (\%) } & Luminal A & $660(11.2 \%)$ \\
\hline & Luminal B $\varangle \mathrm{Her} 2+\square$ & $1752(29.6 \%)$ \\
\hline & Luminal BषHer2 -邓 & $688(11.6 \%)$ \\
\hline & TNBC & $634(10.7 \%)$ \\
\hline & Her2 positive & $744(12.6 \%)$ \\
\hline & Unknown & $1439(24.3 \%)$ \\
\hline \multirow[t]{3}{*}{ ER } & Negative & $1759(29.7 \%)$ \\
\hline & positive & 3959 (66.9\%) \\
\hline & Unknown & 199 (3.4\%) \\
\hline \multirow[t]{3}{*}{ PR } & Negative & 1998 (33.8\%) \\
\hline & positive & 3720 (62.9\%) \\
\hline & Unknown & 199 (3.4\%) \\
\hline \multirow[t]{3}{*}{ HER2 } & Negative & 3466 (58.6\%) \\
\hline & positive & 1419 (24.0\%) \\
\hline & Unknown & 1032 (17.4\%) \\
\hline
\end{tabular}

Page 9/15 


\begin{tabular}{|lll|}
\hline Ki67 & $<14 \%$ & $1034(17.5 \%)$ \\
\hline Comorbidity a & $\geq 14 \%$ & $4480(75.7 \%)$ \\
\hline TC (mmol/L), median (IQR) & Unknown & $403(6.8 \%)$ \\
\hline Mean (SD) & No & $5165 \llbracket 87.3 \% \rrbracket$ \\
\hline TG (mmol/L), median (IQR) & & $752(12.7 \%)$ \\
\hline Mean (SD) & & $4.66[4.12,5.29]$ \\
\hline HDL-C (mmol/L), median (IQR) & & $4.75(0.92)$ \\
\hline Mean (SD) & $1.10[0.82,1.54]$ \\
\hline LDL-C (mmol/L), median (IQR) & $1.31(0.83)$ \\
\hline Mean (SD) & $1.56[1.32,1.84]$ \\
\hline
\end{tabular}

a, Comorbidity for hypertension, diabetes, and chronic kidney disease; ER, estrogen receptor; PR, progesterone receptor; HER2, human epidermal growth factor receptor-2; TNBC, Triple-negative Breast Cancer; TC, Total cholesterol; TG, Triglyceride; HDL-C, HDL cholesterol; LDL-C, LDL cholesterol; 


\begin{tabular}{|c|c|c|c|c|c|c|c|c|c|c|c|c|}
\hline & \multicolumn{2}{|c|}{ Abnormal TC } & \multicolumn{2}{|c|}{ Abnormal LDL-C } & \multicolumn{2}{|c|}{$\begin{array}{l}\text { Abnormal HDL- } \\
\text { C }\end{array}$} & \multicolumn{2}{|c|}{ Abnormal TG } & \multicolumn{2}{|c|}{ Dyslipidemia $^{a}$} & \multicolumn{2}{|l|}{ ASCVD $^{b}$} \\
\hline & $\mathrm{N}(\%)$ & $\mathrm{p}$ & $\mathrm{N}(\%)$ & $\mathrm{p}$ & $\mathrm{N}(\%)$ & $\mathrm{p}$ & $\mathrm{N}(\%)$ & $\mathrm{p}$ & $\mathrm{N}(\%)$ & $\mathrm{p}$ & $\mathrm{N}(\%)$ & $\mathrm{p}$ \\
\hline Age & Total $=5917$ & & & & & & & & & & Total $=978$ & \\
\hline $18-34$ & $4(1.2 \%)$ & $<0.001$ & $\begin{array}{l}4 \\
(1.2 \%)\end{array}$ & $<0.001$ & $\begin{array}{l}9 \\
(2.6 \%)\end{array}$ & 0.148 & $\begin{array}{l}11 \\
(3.2 \%)\end{array}$ & $<0.001$ & $\begin{array}{l}22 \\
(6.4 \%)\end{array}$ & $<0.001$ & $0(0.0 \%)$ & 0.012 \\
\hline $35-44$ & $43(2.3 \%)$ & & $\begin{array}{l}27 \\
(1.4 \%)\end{array}$ & & $\begin{array}{l}68 \\
(3.6 \%)\end{array}$ & & $\begin{array}{l}88 \\
(4.6 \%)\end{array}$ & & $\begin{array}{l}186 \\
(9.7 \%)\end{array}$ & & $12(6.5 \%)$ & \\
\hline $45-54$ & 138 (6.5\%) & & $\begin{array}{l}82 \\
(3.9 \%)\end{array}$ & & $\begin{array}{l}94 \\
(4.5 \%)\end{array}$ & & $\begin{array}{l}178 \\
(8.4 \%)\end{array}$ & & $\begin{array}{l}352 \\
(16.7 \%)\end{array}$ & & $17(4.8 \%)$ & \\
\hline $55-64$ & $\begin{array}{l}152 \\
(13.3 \%)\end{array}$ & & $\begin{array}{l}98 \\
(8.6 \%)\end{array}$ & & $\begin{array}{l}51 \\
(4.5 \%)\end{array}$ & & $\begin{array}{l}147 \\
(12.8 \%)\end{array}$ & & $\begin{array}{l}301 \\
(26.3 \%)\end{array}$ & & $\begin{array}{l}34 \\
(11.3 \%)\end{array}$ & \\
\hline $65-$ & $57(14.0 \%)$ & & $\begin{array}{l}38 \\
(9.3 \%)\end{array}$ & & $\begin{array}{l}23 \\
(5.6 \%)\end{array}$ & & $\begin{array}{l}51 \\
(12.5 \%)\end{array}$ & & $\begin{array}{l}117 \\
(28.7 \%)\end{array}$ & & $\begin{array}{l}12 \\
(10.3 \%)\end{array}$ & \\
\hline BMI & Total $=5902$ & & & & & & & & & & Total $=976$ & \\
\hline Low & $17(6.4 \%)$ & 0.003 & $\begin{array}{l}9 \\
(3.4 \%)\end{array}$ & 0.001 & $\begin{array}{l}1 \\
(0.4 \%)\end{array}$ & $<0.001$ & $\begin{array}{l}6 \\
(2.3 \%)\end{array}$ & $<0.001$ & $\begin{array}{l}22 \\
(8.3 \%)\end{array}$ & $<0.001$ & $3(13.6 \%)$ & 0.059 \\
\hline Normal & $206(5.7 \%)$ & & $\begin{array}{l}123 \\
(3.4 \%)\end{array}$ & & $\begin{array}{l}105 \\
(2.9 \%)\end{array}$ & & $\begin{array}{l}208 \\
(5.8 \%)\end{array}$ & & $\begin{array}{l}462 \\
(12.9 \%)\end{array}$ & & $42(9.1 \%)$ & \\
\hline Overweight & $29(7.1 \%)$ & & $\begin{array}{l}27 \\
(6.6 \%)\end{array}$ & & $\begin{array}{l}39 \\
(9.5 \%)\end{array}$ & & $\begin{array}{l}63 \\
(15.4 \%)\end{array}$ & & $\begin{array}{l}116 \\
(28.3 \%)\end{array}$ & & $11(9.5 \%)$ & \\
\hline Obese & $140(8.5 \%)$ & & $\begin{array}{l}89 \\
(5.4 \%)\end{array}$ & & $\begin{array}{l}100 \\
(6.1 \%)\end{array}$ & & $\begin{array}{l}198 \\
(12.1 \%)\end{array}$ & & $\begin{array}{l}376 \\
(22.9 \%)\end{array}$ & & $18(4.8 \%)$ & \\
\hline $\begin{array}{l}\text { Menopause } \\
\text { status }\end{array}$ & Total $=5917$ & & & & & & & & & & Total $=978$ & \\
\hline No & 112 (3.1\%) & $<0.001$ & $\begin{array}{l}72 \\
(2.0 \%)\end{array}$ & $<0.001$ & $\begin{array}{l}135 \\
(3.7 \%)\end{array}$ & 0.029 & $\begin{array}{l}201 \\
(5.5 \%)\end{array}$ & $<0.001$ & $\begin{array}{l}400 \\
(10.9 \%)\end{array}$ & $<0.001$ & $17(4.2 \%)$ & 0.001 \\
\hline Yes & $\begin{array}{l}282 \\
(12.5 \%)\end{array}$ & & $\begin{array}{l}177 \\
(7.9 \%)\end{array}$ & & $\begin{array}{l}110 \\
(4.9 \%)\end{array}$ & & $\begin{array}{l}274 \\
(12.2 \%)\end{array}$ & & $\begin{array}{l}578 \\
(25.7 \%)\end{array}$ & & $\begin{array}{l}58 \\
(10.0 \%)\end{array}$ & \\
\hline Stage & Total $=5617$ & & & & & & & & & & Total $=936$ & \\
\hline 0 & $21(9.4 \%)$ & 0.237 & $\begin{array}{l}13 \\
(5.8 \%)\end{array}$ & 0.324 & $\begin{array}{l}7 \\
(3.1 \%)\end{array}$ & 0.544 & $\begin{array}{l}10 \\
(4.5 \%)\end{array}$ & 0.124 & $\begin{array}{l}32 \\
(14.3 \%)\end{array}$ & 0.487 & $4(12.5 \%)$ & 0.595 \\
\hline$\otimes$ & $99(7.4 \%)$ & & $\begin{array}{l}56 \\
(4.2 \%)\end{array}$ & & $\begin{array}{l}48 \\
(3.6 \%)\end{array}$ & & $\begin{array}{l}99 \\
(7.4 \%)\end{array}$ & & $\begin{array}{l}212 \\
(15.9 \%)\end{array}$ & & $19(9.0 \%)$ & \\
\hline$\nabla$ & 177 (6.4\%) & & $\begin{array}{l}109 \\
(3.9 \%)\end{array}$ & & $\begin{array}{l}116 \\
(4.2 \%)\end{array}$ & & $\begin{array}{l}234 \\
(8.5 \%)\end{array}$ & & $\begin{array}{l}463 \\
(16.7 \%)\end{array}$ & & 32 (6.9\%) & \\
\hline$\nabla$ & 83 (6.4\%) & & $\begin{array}{l}64 \\
(4.9 \%)\end{array}$ & & $\begin{array}{l}59 \\
(4.6 \%)\end{array}$ & & $\begin{array}{l}112 \\
(8.7 \%)\end{array}$ & & $\begin{array}{l}229 \\
(17.7 \%)\end{array}$ & & $18(7.9 \%)$ & \\
\hline Subtypes & Total $=4478$ & & & & & & & & & & Total $=716$ & \\
\hline Luminal A & $42(6.4 \%)$ & 0.982 & $\begin{array}{l}23 \\
(3.5 \%)\end{array}$ & 0.271 & $\begin{array}{l}19 \\
(2.9 \%)\end{array}$ & 0.490 & $\begin{array}{l}39 \\
(5.9 \%)\end{array}$ & 0.393 & $\begin{array}{l}86 \\
(13.0 \%)\end{array}$ & 0.246 & $6(7.0 \%)$ & 0.912 \\
\hline $\begin{array}{l}\text { Luminal B } \\
(\operatorname{Her} 2+)\end{array}$ & 113 (6.4\%) & & $\begin{array}{l}79 \\
(4.5 \%)\end{array}$ & & $\begin{array}{l}68 \\
(3.9 \%)\end{array}$ & & $\begin{array}{l}142 \\
(8.1 \%)\end{array}$ & & $\begin{array}{l}289 \\
(16.5 \%)\end{array}$ & & 25 (8.7\%) & \\
\hline $\begin{array}{l}\text { Luminal B } \\
\text { 邓Her2 }-\rrbracket\end{array}$ & $42(6.1 \%)$ & & $\begin{array}{l}32 \\
(4.7 \%)\end{array}$ & & $\begin{array}{l}28 \\
(4.1 \%)\end{array}$ & & $\begin{array}{l}57 \\
(8.3 \%)\end{array}$ & & $\begin{array}{l}115 \\
(16.7 \%)\end{array}$ & & $9(7.8 \%)$ & \\
\hline TNBC & $43(6.8 \%)$ & & $\begin{array}{l}24 \\
(3.8 \%)\end{array}$ & & $\begin{array}{l}29 \\
(4.6 \%)\end{array}$ & & $\begin{array}{l}53 \\
(8.4 \%)\end{array}$ & & $\begin{array}{l}108 \\
(17.0 \%)\end{array}$ & & $9(8.3 \%)$ & \\
\hline $\begin{array}{l}\text { Her2 } \\
\text { positive }\end{array}$ & $45(6.0 \%)$ & & $\begin{array}{l}21 \\
(2.8 \%)\end{array}$ & & $\begin{array}{l}34 \\
(4.6 \%)\end{array}$ & & $\begin{array}{l}56 \\
(7.5 \%)\end{array}$ & & $\begin{array}{l}118 \\
(15.9 \%)\end{array}$ & & $7(5.9 \%)$ & \\
\hline ER & Total $=5718$ & & & & & & & & & & Total $=943$ & \\
\hline Negative & 118 (6.7\%) & 0.749 & 60 & 0.074 & 77 & 0.574 & 142 & 0.999 & 292 & 0.913 & $22(7.5 \%)$ & 0.999 \\
\hline
\end{tabular}




\begin{tabular}{|c|c|c|c|c|c|c|c|c|c|c|c|c|}
\hline & & & $(3.4 \%)$ & & $(4.4 \%)$ & & $(8.1 \%)$ & & $(16.6 \%)$ & & & \\
\hline Positive & $255(6.4 \%)$ & & $\begin{array}{l}177 \\
(4.5 \%)\end{array}$ & & $\begin{array}{l}159 \\
(4.0 \%)\end{array}$ & & $\begin{array}{l}319 \\
(8.1 \%)\end{array}$ & & $\begin{array}{l}651 \\
(16.4 \%)\end{array}$ & & $50(7.7 \%)$ & \\
\hline PR & Total $=5718$ & & & & & & & & & & Total $=943$ & \\
\hline Negative & $138(6.9 \%)$ & 0.421 & $\begin{array}{l}74 \\
(3.7 \%)\end{array}$ & 0.247 & $\begin{array}{l}87 \\
(4.4 \%)\end{array}$ & 0.574 & $\begin{array}{l}159 \\
(8.0 \%)\end{array}$ & 0.872 & $\begin{array}{l}343 \\
(17.2 \%)\end{array}$ & 0.331 & $26(7.6 \%)$ & 0.999 \\
\hline Positive & $235(6.3 \%)$ & & $\begin{array}{l}163 \\
(4.4 \%)\end{array}$ & & $\begin{array}{l}149 \\
(4.0 \%)\end{array}$ & & $\begin{array}{l}302 \\
(8.1 \%)\end{array}$ & & $\begin{array}{l}600 \\
(16.1 \%)\end{array}$ & & $46(7.7 \%)$ & \\
\hline HER2 & Total $=4885$ & & & & & & & & & & Total $=791$ & \\
\hline Negative & $216(6.2 \%)$ & 0.473 & $\begin{array}{l}133 \\
(3.8 \%)\end{array}$ & 0.578 & $\begin{array}{l}137 \\
(4.0 \%)\end{array}$ & 0.890 & $\begin{array}{l}272 \\
(7.8 \%)\end{array}$ & 0.568 & $\begin{array}{l}550 \\
(15.9 \%)\end{array}$ & 0.359 & $38(6.9 \%)$ & 0.588 \\
\hline Positive & 97 (6.8\%) & & $\begin{array}{l}60 \\
(4.2 \%)\end{array}$ & & $\begin{array}{l}58 \\
(4.1 \%)\end{array}$ & & $\begin{array}{l}119 \\
(8.4 \%)\end{array}$ & & $\begin{array}{l}241 \\
(17.0 \%)\end{array}$ & & $20(8.3 \%)$ & \\
\hline KI67 & Total $=5514$ & & & & & & & & & & Total $=912$ & \\
\hline$<14 \%$ & $64(6.2 \%)$ & 0.732 & $\begin{array}{l}36 \\
(3.5 \%)\end{array}$ & 0.253 & $\begin{array}{l}43 \\
(4.2 \%)\end{array}$ & 0.999 & $\begin{array}{l}78 \\
(7.5 \%)\end{array}$ & 0.501 & $\begin{array}{l}164 \\
(15.9 \%)\end{array}$ & 0.545 & $8(4.9 \%)$ & 0.170 \\
\hline$>=14 \%$ & $293(6.5 \%)$ & & $\begin{array}{l}194 \\
(4.3 \%)\end{array}$ & & $\begin{array}{l}186 \\
(4.2 \%)\end{array}$ & & $\begin{array}{l}369 \\
(8.2 \%)\end{array}$ & & $\begin{array}{l}748 \\
(16.7 \%)\end{array}$ & & $63(8.4 \%)$ & \\
\hline
\end{tabular}

Abnormal TC, TC $\geq 6.2 \mathrm{mmol} / \mathrm{L}$; Abnormal LDL-C, LDL-C $\geq 4.1 \mathrm{mmol} / \mathrm{L}$; Abnormal HDL-C, HDL-C $1.0 \mathrm{mmol} / \mathrm{L}$; Abnormal TG, TG $\geq 2.3 \mathrm{mmol} / \mathrm{L}$; a, Any abnormality of the blood lipids index is defined as dyslipidemia ;b, ASCVD, LDL-C $\geq 4.9 \mathrm{mmol} / \mathrm{L} \square T C \geq 7.2 \mathrm{mmol} / \mathrm{L}$; ER, estrogen receptor; $P R$, progesterone receptor; HER2, human epidermal growth factor receptor-2; TNBC, Triple-negative Breast Cancer; TC, Total cholesterol; TG, Triglyceride; HDL-C, HDL cholesterol; LDL-C, LDL cholesterol;

\begin{tabular}{|c|c|c|c|c|c|c|c|c|c|}
\hline \multirow[t]{2}{*}{ Menopause } & \multicolumn{4}{|l|}{ LDL-C } & \multicolumn{3}{|l|}{ TC } & \multirow[b]{2}{*}{$\begin{array}{l}\text { Adjusted } \mathrm{HR}^{\star} \\
\text { [95\%Cl] }\end{array}$} & \multirow[b]{2}{*}{$P$} \\
\hline & $\begin{array}{l}\text { Crude HR } \\
{[95 \% \mathrm{Cl}]}\end{array}$ & $P$ & $\begin{array}{l}\text { Adjusted HR* } \\
\text { [95\%Cl] }\end{array}$ & $P$ & Crude HR [95\%Cl] & $P$ & & & \\
\hline Al vs SERM & $\begin{array}{l}4.22[1.52 \text { - } \\
11.71]\end{array}$ & 0.006 & $\begin{array}{l}3.92[1.41 \text { - } \\
10.91]\end{array}$ & 0.009 & 3.15 [ $1.58-6.29]$ & 0.001 & & $\begin{array}{l}3.15[1.58- \\
6.29]\end{array}$ & 0.001 \\
\hline ANA vs TAM & $\begin{array}{l}6.02[1.82- \\
19.83]\end{array}$ & 0.003 & $\begin{array}{l}6.17[1.87- \\
20.37]\end{array}$ & 0.003 & 4.07 [ 1.92 - 8.62] & $<0.001$ & & $\begin{array}{l}4.07[1.92- \\
8.62]\end{array}$ & $<0.001$ \\
\hline LET vs TAM & $\begin{array}{l}4.92[1.44- \\
16.78]\end{array}$ & 0.011 & $\begin{array}{l}5.00[1.46- \\
17.07]\end{array}$ & 0.010 & $2.95[1.34-6.49]$ & 0.007 & & $\begin{array}{l}2.77[1.25- \\
6.10]\end{array}$ & 0.012 \\
\hline ANA vs LET & $\begin{array}{l}1.22[0.67- \\
2.24]\end{array}$ & 0.518 & $\begin{array}{l}1.18[0.64- \\
2.18]\end{array}$ & 0.593 & 1.38 [ $0.86-2.22]$ & 0.179 & & $\begin{array}{l}1.38[0.86- \\
2.22]\end{array}$ & 0.1792 \\
\hline \multirow[t]{2}{*}{ Premenopause } & LDL-C & & & & TC & & & & \\
\hline & $\begin{array}{l}\text { Crude HR } \\
{[95 \% \mathrm{Cl}]}\end{array}$ & $P$ & $\begin{array}{l}\text { Adjusted HR* } \\
\text { [95\%Cl] }\end{array}$ & $P$ & Crude HR [95 & & $P$ & $\begin{array}{l}\text { Adjusted } \mathrm{HR}^{\star} \\
\text { [95\%Cl] }\end{array}$ & $P$ \\
\hline $\begin{array}{l}\text { OFS+Al vs } \\
\text { SERM }\end{array}$ & $\begin{array}{l}7.5[3.54 \text { - } \\
15.87]\end{array}$ & $<0.001$ & $\begin{array}{l}6.71[3.16- \\
14.26]\end{array}$ & $<0.001$ & $5.13[2.99-8$ & & $<0.001$ & $\begin{array}{l}3.50[1.74 \text { - } \\
7.02]\end{array}$ & $<0.001$ \\
\hline $\begin{array}{l}\text { OFS+ANA vs } \\
\text { TAM }\end{array}$ & $\begin{array}{l}12.63[5.34- \\
29.86]\end{array}$ & $<0.001$ & $\begin{array}{l}1086[4.59 \text { - } \\
25.71]\end{array}$ & $<0.001$ & $5.86[3.00-1$ & $.45]$ & $<0.001$ & $\begin{array}{l}4.05[1.72- \\
9.55]\end{array}$ & 0.001 \\
\hline $\begin{array}{l}\text { OFS+LET vs } \\
\text { TAM }\end{array}$ & $\begin{array}{l}4.32[1.19- \\
15.70]\end{array}$ & 0.026 & $\begin{array}{l}3.66[1.01- \\
13.30]\end{array}$ & 0.049 & $6.25[3.09-1$ & .67] & $<0.001$ & $\begin{array}{l}4.66[2.02- \\
10.72]\end{array}$ & $<0.001$ \\
\hline
\end{tabular}

SERM, selective estrogen receptor modulator; TAM, tamoxifen; TOR, Toremifene; Al, aromatase inhibitor; ANA, Anastrozole; LET, Letrozole; EXE, Exemestane; OFS, ovarian function suppression; TC, Total cholesterol; LDL-C, LDL cholesterol; * In each comparison group, we establish univariate COX regression model for each feature and involved significant variables $(p<0.05)$ into the final multivariate COX regression model to adjust the crude HR.

\section{Figures}




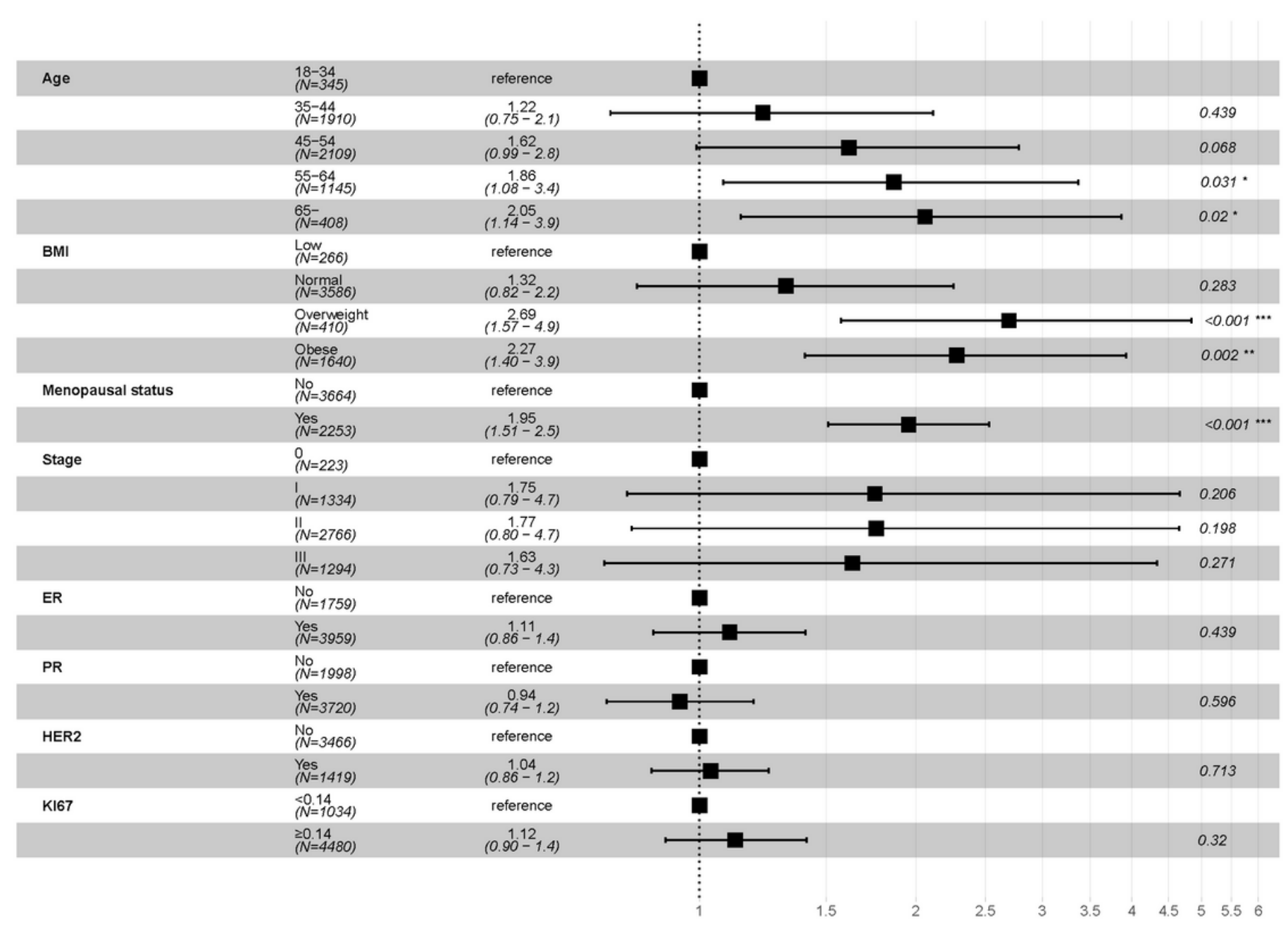

\section{Figure 1}

Odds ratios for dyslipidemia in early breast cancer patients at initial diagnosis BMI was divided into Low (BMI < 18.5), Normal (18.5 $\leq \mathrm{BMl} \leq 23.9)$, Overweight, (24.0 $\leq \mathrm{BMI} \leq 27.9)$, and Obese (BMI $\geq 28.0)$; ER, estrogen receptor; PR, progesterone receptor; HER2, human epidermal growth factor receptor-2; 

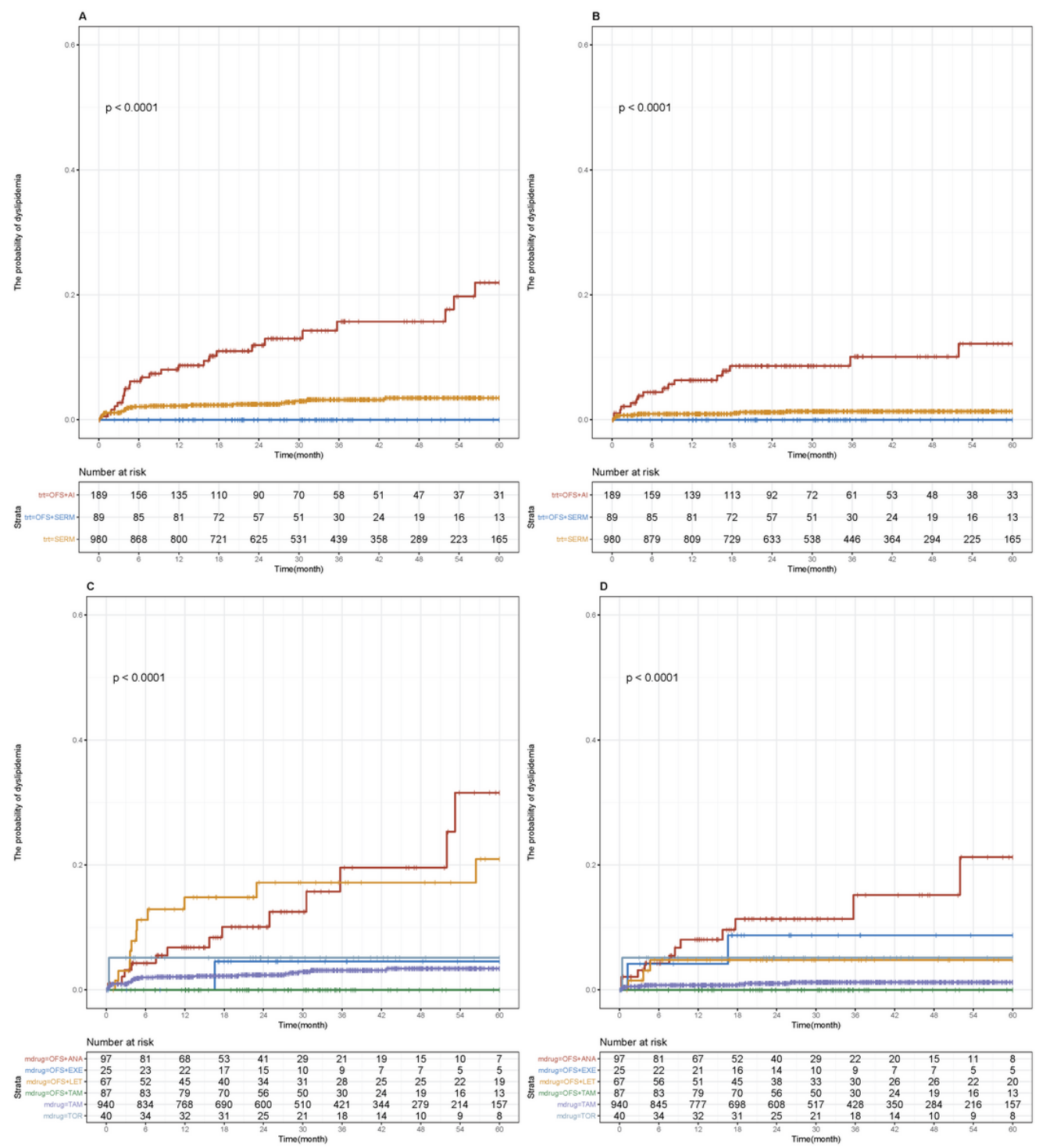

\section{Figure 2}

Cumulative abnormal TC and LDL-C incidence among early breast cancer pre-menopause patients for different endocrine therapy Cumulative curves showing TC ( $A$ and $C$ ) and LDL-C (B and D) dyslipidemia incidence. P values were obtained from log-rank tests for comparisons of abnormal TC and LDL-C incidence between different endocrine therapy groups. SERM, selective estrogen receptor modulator; TAM, tamoxifen; TOR, Toremifene; Al, aromatase inhibitor; ANA, Anastrozole; LET, Letrozole; EXE, Exemestane; OFS, ovarian function suppression; TC, Total cholesterol; TG, Triglyceride; HDL-C, HDL cholesterol; LDL-C, LDL cholesterol. 

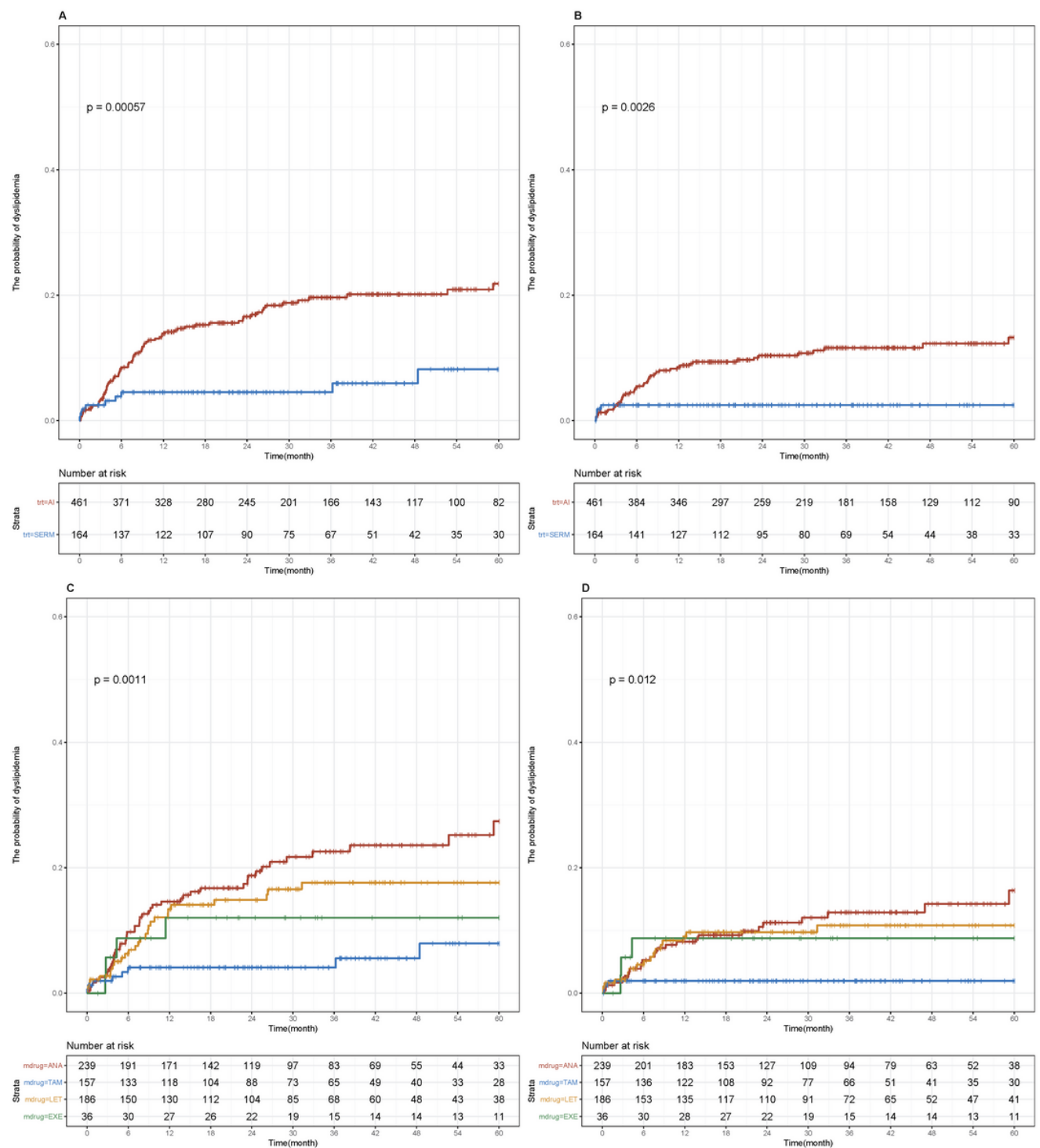

\section{Figure 3}

Cumulative abnormal TC and LDL-C incidence among early breast cancer menopause patients for different endocrine therapy Cumulative curves showing TC (A and C) and LDL-C (B and D) dyslipidemia incidence. P values were obtained from log-rank tests for comparisons of abnormal TC and LDL-C incidence between different endocrine therapy groups.S ERM, selective estrogen receptor modulator; TAM, tamoxifen; TOR, Toremifene; Al, aromatase inhibitor; ANA, Anastrozole; LET, Letrozole; EXE, Exemestane; TC, Total cholesterol; TG, Triglyceride; HDL-C, HDL cholesterol; LDL-C, LDL cholesterol.

\section{Supplementary Files}

This is a list of supplementary files associated with this preprint. Click to download.

- Supplement.docx 